\title{
A IMPORTÂNCIA DA ÉTICA PROFISSIONAL DO ESTETICISTA NO RELACIONAMENTO COM O CLIENTE
}

\section{ARTIGO DE REVISÃO}

GOES, Patrícia de Campos ${ }^{1}$

BARRETO, Larissa Cerqueira Cardoso²

GOES, Patrícia de Campos. BARRETO, Larissa Cerqueira Cardoso. A importância da ética profissional do esteticista no relacionamento com o cliente. Revista Científica Multidisciplinar Núcleo do Conhecimento. Ano 04, Ed. 07, Vol. 13, pp. 153172. Julho de 2019. ISSN: 2448-0959

\section{RESUMO}

O presente trabalho tem como objetivo demonstrar a importância da ética profissional do esteticista no relacionamento com o cliente. Para demonstrar a importância do agir com ética, discorremos acerca dos conceitos de ética e moral, sobre a excelência da conduta ética nos principais contextos que norteiam o local de trabalho do tecnólogo em estética e cosmética, e do quão importante é a existência do código de ética para esta categoria profissional, por ser um documento que especifica, além dos direitos e

\footnotetext{
${ }^{1}$ Graduada em Economia (1994); graduada em Direito (2008); Graduanda em Estética e Cosmética.
}

2 Bacharel em Fisioterapia pela Faculdade Estácio de Sergipe (2012). Pós-graduada em Fisioterapia Dermatofuncional pela Universidade Estácio de Sá-RJ. Especialista em Fisioterapia Dermatofuncional pela Associação Brasileira de Fisioterapia Dermatofuncional/Conselho Federal de Fisioterapia e Terapia Ocupacional (ABRAFIDEF/COFFITO). Formação em Pilates pela Qualifica. Formação em Terapia Bioortomolecular pelo Instituto Isa Prudome. Ministrante de diversos cursos na área de Fisioterapia Dermatofuncional/Estética/Embelezamento. 
deveres, o que é vetado eticamente ao exercício da profissão e as possíveis punições em caso de desobediência ao que nele está determinado. A metodologia utilizada foi dividida em duas etapas, sendo a primeira uma pesquisa bibliográfica, onde obras científicas e literárias solidificaram a fundamentação teórica, e a segunda, uma pesquisa quantitativa por meio de questionário aplicado a estudantes do curso de Estética e Cosmética da Universidade Tiradentes, atuantes na área. As respostas obtidas no questionário indicaram que, embora a maioria admita a importância do Código de Ética, alguns entrevistados, por opção, ainda possuem atitudes antiéticas. Por outro lado, a maior parte deles já presenciou atos praticados por profissionais que não condizem com a ética.

Palavras-chave: ética, ética profissional, ética na estética.

\section{INTRODUÇÃO}

Durante o percurso acadêmico do estudante de estética, diversas disciplinas teóricas e práticas são-Ihe apresentadas afim de torná-lo capacitado intelectualmente e tecnicamente para exercitar com propriedade e segurança a profissão. Entretanto, um bom profissional precisa, além do conhecimento acerca dos inúmeros procedimentos que a profissão permite que sejam por ele realizados, possuir consciência e reflexão no tocante aos valores éticos tanto no contato direto com o cliente, como no ambiente de trabalho, na biossegurança, no contexto comercial e no sigilo profissional (BATAGLIA e BORTOLANZA, 2012).

No Brasil, o Ministério da Educação - MEC, sugeriu formalmente, em 1992, a inclusão da disciplina de ética nas grades curriculares de alguns cursos de graduação, destacando a relevância do desenvolvimento de uma postura ética nos futuros profissionais das diferentes áreas do conhecimento (ARRUDA, RAMOS, 2003, apud, OLIVEIRA et al. 2010).

A ética é indispensável ao profissional visto que "o fazer", que diz respeito à competência para o exercício da profissão e "o agir", que diz respeito à conduta profissional, estão interligados. Por ter como base uma filosofia de valores 
compatíveis com a natureza e o fim de todo o ser humano, o "agir" da pessoa humana está condicionado às premissas básicas "o que é" o homem e "para que vive". Assim, a capacitação técnica ou científica precisa estar em comunhão com os princípios éticos essenciais (MOTTA, 1984).

Todo ser ético pensa antes de agir, e age sabendo que terá que assumir os resultados (CHAUI, 2000). Desta forma, ao profissional de estética, cabe a responsabilização pelas consequências de atitudes que porventura venham confrontar os valores impostos pela sociedade ou arque prejuízo ao cliente. A ética está intrinsecamente ligada à noção de autonomia individual (MAIO apud SOUZA, ARAÚJO, 2015). Agindo com ética, o profissional intelectualmente qualificado poderá proporcionar ao cliente, segurança técnica e emocional na execução dos procedimentos.

No intuito de responder ao problema por este trabalho apresentado, qual seja, o motivo pelo qual a ética profissional do esteticista é importante no relacionamento com o cliente, temos como hipótese a necessidade do esteticista possuir, além do conhecimento técnico e intelectual, a ética no exercício da profissão afim de realizar com profissionalismo suas atividades, cuja relevância são os diversos casos de procedimentos que, por desrespeito às condutas éticas, vem provocando prejuízos materiais e físicos ao cliente. Esta pesquisa possui como objetivo geral, identificar junto a alunos do curso de estética atuantes na área, a percepção da ética no exercício da profissão. Para atendê-lo, faz-se necessário descrever os conceitos de ética e moral, demonstrar a ética na conduta profissional, na anamnese e informações ao cliente, na biossegurança, no contexto comercial, no sigilo profissional e sobre o código de ética, bem como analisar as respostas obtidas pela população selecionada.

\section{FUNDAMENTAÇÃO TEÓRICA}

Este capítulo dedica-se a mostrar o referencial teórico que sustenta o objetivo do estudo. Será trazido à baila a definição conceitual de Ética, sua relação com Moral, suas aplicações no contexto da estética, bem como a importância da criação de um Código de Ética para os esteticistas. 


\section{1 ÉTICA X MORAL}

Os termos ética e moral frequentemente são usados como sinônimos gerando confusão e dificultando a comunicação e a elaboração do pensamento de quem tem necessidade de usá-los (PEDRO, 2014). Apesar da confusão, os termos são bem diferentes. Ética, que deriva do grego ethos, significa caráter do indivíduo na sociedade, e moral, que deriva do latim morale, significa costume ou conjunto de regras adquiridas com o passar do tempo (BARROS, 2010).

Enquanto a ética se fundamente em três pré-requisitos: percepção de conflitos (consciência); autonomia (condição de posicionar-se de forma ativa e autônoma entra a razão e a emoção); e coerência, a moral pressupõe três características: seus valores não são questionados; seus valores são impostos; e a desobediência às regras pressupõe castigo (COHEN, SEGRE, 1995). Em suma, ética são as boas ações de forma livre e espontânea da pessoa, e moral é um conjunto obrigatório de normas que regem a conduta humana (RICOEUR, 1990).

\section{2 ÉTICA NA CONDUTA PROFISSIONAL}

Um bom profissional deve, além de possuir conhecimento técnico e legal acerca dos procedimentos que por ele podem ser realizados e estar cumprindo rigorosamente os cuidados no tocante à biossegurança, vestir-se adequadamente, evitando trajes incompatíveis com o ambiente de trabalho e possuir comportamento educado e gentil com o cliente e demais pessoas que, de forma contínua ou esporádica, frequentem o local.

Em relação ao acolhimento e tratamento do cliente, é de suma importância que o zelo e o respeito estejam presentes em todas as atitudes. A ASSOCEMSP (Associação dos Profissionais de Cosmetologia Estética e Maquilagem do Estado de São Paulo), em seu código de ética, enumera nos incisos I a III do art. $7^{\circ}$, Capítulo III, que trata do respeito com o cliente, deveres e obrigações que o esteticista deve possuir em relação ao cliente no tocante ao comportamento habitual na lida diária do atendimento, dada 
a diversidade da clientela, visto que, identidade, religião, convicções políticas e filosóficas não são fatores que devam influenciar no atendimento.

Art. $7^{0}$ - O Esteticista em relação aos clientes possui os seguintes deveres e obrigações:

I - Respeitar a individualidade, dignidade e direitos fundamentais da pessoa humana;

II- Saber ouvir seu cliente e demostrando empatia;

III - Respeitar as convicções religiosas, políticas e filosóficas do cliente.

\section{3 ÉTICA NA ANAMNESE E NAS INFORMAÇÕES AO CLIENTE}

É no preenchimento da ficha de anamnese que o profissional tem o primeiro contato com os dados informativos e anseios do cliente. É quando, sob forma de entrevista, que deve ser feita sem pressa, o profissional coleta as informações necessárias que, analisadas, determinarão o melhor procedimento a ser realizado (SWARTZ, 2015; D'EPĖSE, 1879; BICKLEY, 2015). Um dos fatores que mais influenciam no alcance da anamnese adequada é o tempo que se dedica a ela. Caso o profissional acelere a entrevista, poderá haver falhas relevantes que poderão comprometer o objetivo a ser alcançado (BALDUINO, 2012).

A Federação Brasileira dos Profissionais Esteticistas (FEBRAPE, 2003), informa no inciso V do artigo 3ํㅡㄹ do Código de Ética dos esteticistas, que é seu dever, fazer prévia anamnese estética do cliente, que se submeter ao seu procedimento.

Art. $3^{\circ}$ - São deveres do esteticista:

$[\ldots]$

V - Fazer prévia anamnese estética do cliente, que se submeter ao seu procedimento. 
A ASSOCEMSP (Associação dos Profissionais de Cosmetologia Estética e Maquilagem do Estado de São Paulo), no inciso IV do artigo $7^{\circ}$ do seu código de ética, informa que o esteticista deve informar ao cliente sua condição aos procedimentos que lhe serão aplicados.

Art. $7^{0}$ - O Esteticista em relação aos clientes possui os seguintes deveres e obrigações:

\section{$[\ldots]$}

IV - Informar antecipadamente, ao cliente, sua condição, aos procedimentos e técnicas a serem aplicadas, conforme as possibilidades e limites profissionais do esteticista.

Assim que o procedimento é definido, seu processo, riscos, cuidados e resultados esperados devem ser pontuados de forma clara ao cliente e suas possíveis dúvidas, sanadas. Desta forma, o relacionamento entre eles tomará bases sólidas de confiança.

\section{4 ÉTICA NA BIOSSEGURANÇA}

Quando falamos em estética, um grande leque se abre, e nele temos várias atividades, onde em algumas são utilizados apenas cosméticos, noutras, produtos químicos, e ainda objetos perfurantes e equipamentos.

Tendo em vista que grande parcela de profissionais atuantes na estética não recebeu capacitação, deduz-se que a biossegurança seja um tema pouco conhecido, favorecendo assim a transmissão silenciosa de micro-organismos em razão do ambiente desprotegido (JOHNSON et al., 2001; WAZIR et al.,2008).

No contexto da estética, a biossegurança tem o objetivo de controlar e minimizar os riscos químicos e biológicos. Para tanto, destaca-se a importância do uso de Equipamentos de Proteção Individual (EPI's), da higienização das mãos, do descarte de materiais perfuro cortantes, da cobertura vacinal e do processamento de 
dispositivos usados na prática (NEVES et al., 2007). A biossegurança abrange também cuidados que incluem os Equipamentos de Proteção Coletiva (EPC's), desinfecção e esterilização de todos os instrumentos não descartáveis, sejam perfuro cortantes ou não (TONETA, AGOSTINI, 2017), além de cumprir as regras definidas pela Agência Nacional de Vigilância Sanitária (ANVISA), no tocante ao armazenamento, controle de produtos e manutenção dos equipamentos.

\section{5 ÉTICA NO CONTEXTO COMERCIAL}

Com a globalização e a competitividade do mercado, e visando a satisfação do cliente, bem como dos funcionários, fornecedores e sociedade em geral, a busca por profissionais que atendam aos princípios éticos tem aumentado (BASTOS; YAMAMOTO; RODRIGUES, 2015). Desta forma, o profissional, no intuito de preservar sua integridade individual e da classe, deve impugnar qualquer consentimento ou envolvimento em trabalhos e negócios duvidosos (DOTTO, 2002).

É claro que a prática da atividade visa, além do reconhecimento, lucro. Porém, este deve ser obtido em razão de uma concorrência leal, e não do uso de artifícios que venham denegrir a imagem e competência dos colegas de profissão. Os incisos III e VI do artigo $4^{\circ}$ do código de estética dos esteticistas, informam a proibição da prática de atos desleais com colegas de profissão, bem como a prática de qualquer tipo de constrangimento ao colega de profissão visando para si o seu emprego, cargo ou função. Como exemplo de ato desleal, podemos citar a difamação do trabalho alheio e a utilização de ideia de outrem, afim da obtenção de lucro e posição superior no ambiente de trabalho (FEBRAPE, 2003).

Art. $4^{\circ}$ - Das proibições aos esteticistas:

III- praticar atos de deslealdade com os colegas de profissão;

$[\ldots]$ 
VI- Considera-se falta de ética da moral profissional, causar qualquer tipo de constrangimento a outro esteticista, visando, com isso, conseguir para si o seu emprego, cargo ou função.

Vale ressaltar que , uma boa empresa, além de apresentar lucro, deve oferecer um ambiente moralmente gratificante, permitindo que as pessoas desenvolvam seus conhecimentos especializados (ARRUDA, WHITAKER e RAMOS, 2003).

\section{6 ÉTICA NO SIGILO PROFISSIONAL}

No dicionário Aurélio (FERREIRA, 2006), "sigilo" encontra-se registrado como sinônimo de segredo. Já o "sigilo profissional" é referido como sendo o "dever ético que impede a evolução de assuntos confidenciais ligados à profissão".

Ao ser centralizado na necessidade e direito do cidadão à intimidade, o segredo profissional passou a ter fundamentação mais rigorosa, tornando-se entendido como confidencialidade, transformando-se num direito-dever, isto é, o direito de uma parte gera dever da outra. Desta forma, sendo a confidencialidade um direito do cliente, ao profissional é gerada uma obrigação específica (LOCH, 2003; GRACIA, 1998).

Para que o tratamento seja eficaz e o melhor objetivo seja alcançado, o profissional necessita que o cliente the dê determinadas informações (KOTTOW apud PERES et al., 2008). Estas informações não devem ser tornadas públicas, visto que "toda e qualquer informação compartilhada deve ser respeitada e utilizada exclusivamente para o fim pela qual foi revelada" (STYFFE, 1997, p.21-8). O sigilo é devido por todos que, em razão da sua atividade profissional, tiverem acesso aos dados pessoais do cliente (GRACIA apud D'ESPINDULA, 2017). O dever de guardar sigilo não é apenas ético, mas legal. A Constituição Brasileira de 1988, no título referente aos princípios fundamentais, assegura:

Art. 5ำ Todos são iguais perante a lei, sem distinção de qualquer natureza, garantindo-se aos brasileiros e aos estrangeiros residentes no 
país a inviolabilidade do direito à vida, à liberdade, à igualdade, à segurança e à propriedade, nos termos seguintes:

\section{$[\ldots]$}

X - São invioláveis a intimidade, a vida privada, a honra e a imagem das pessoas, assegurando o direito à indenização, pelo dano material ou moral decorrente de sua violação;

Afim de proteger o caráter de confiança nas relações profissionais, o sigilo de informações é garantido pelo Código Penal Brasileiro (DECRETO LEI nํㅜ 2.848 de 07 de dezembro de 1940), que descreve no seu artigo 154, o delito de violação de sigilo profissional:

Art. 154 - Revelar alguém, sem justa causa, segredo, de que tem ciência em razão de função, ministério, ofício ou profissão, e cuja revelação possa produzir dano a outrem:

Pena - detenção, de três meses a um ano, ou multa.

\subsection{CÓDIGO DE ÉTICA}

O objetivo principal de um código de ética é sintetizado por quatro elementos: competência, sigilo, integridade e objetividade. A competência diz respeito ao nível de preparação técnico-profissional e à aderência às normas e preceitos legais, bem como a capacidade de preparar relatórios claros e completos. O sigilo demonstra o grau de reserva que o profissional tem com as informações que lhe são confiadas por clientes. A integridade demonstra a conduta do profissional diante da sua classe, clientes e concorrentes, e pode ser desmembrada em fatores que vão desde o seu comportamento social até as suas atitudes individuais. A objetividade demonstra 0 grau de clareza que o profissional tem no trato e na transmissão das informações aos clientes, bem como a evidenciação dos dados relevantes que possam influenciar as decisões por parte deles (LISBOA, 1997). 
Embora alguns elementos da ética profissional sejam aplicáveis a qualquer profissão em razão de serem universais, tais como honestidade, competência e responsabilidade, cada profissão deve ter um Código de Ética próprio, contemplando direitos, obrigações, atividades, responsabilidades, proibições e impedimentos, tendo em vista sua área de atuação, pois além de enaltecer a profissão, dá amparo ao cliente em eventuais dúvidas. Para que as regras fossem aplicadas aos profissionais de estética, fundou-se, em 08 de julho de 2003, a Federação Brasileira dos Profissionais Esteticistas (FEBRAPE), que além de buscar unificar as associações de Esteticistas, dispõe sobre a regulamentação destes profissionais e os representa diante dos governos, instituições e entidades (SOUZA, ARAUJO, 2015).

\section{METODOLOGIA}

Duas etapas foram realizadas para o desenvolvimento do presente trabalho. Inicialmente, por meio de consultas em literaturas científicas relacionadas ao tema, utilizando-se da combinação das palavras chave: profissional, ética, moral, ética profissional, código de ética, esteticista, estética, biossegurança, sigilo profissional, cliente, comportamento profissional, na Constituição Federal, Código Penal, ANVISA, ASSOCEMSP, FEBRAPE e MEC, foi realizada a revisão bibliográfica. Os artigos selecionados foram publicados entre 2001 e 2017.

Em seguida, foi realizada uma pesquisa quantitativa, cujo instrumento de coleta foi um questionário composto por quatro perguntas fechadas, aplicado a 50 alunos do curso de Estética e Cosmética da Universidade Tiradentes, atuantes na área, que o responderam nas dependências da Universidade, entre outubro e novembro de 2018.

Os dados obtidos foram tabulados no programa Microsoft Excel 2016 e compuseram os resultados. Levando em consideração o fato dos voluntários já atuarem na área de estética, e afim de obter respostas reais, o anonimato e sigilo de todas as informações foi garantido. Desta forma, não houve risco de constrangimento ou incômodo em responder o questionário, nem de comprometê-los profissionalmente. Vale ressaltar que a identidade dos voluntários não possui relevância no objetivo deste estudo. 


\section{RESULTADOS E DISCUSSÕES}

No intuito de saber a percepção da prática da ética, bem como o quão entendem ser importante a existência de um Código de Ética, cinquenta alunos do curso de Estética e Cosmética da Universidade Tiradentes, atuantes na área, responderam um questionário composto por quatro perguntas diretas voltadas ao tema desta pesquisa. Como resultado, obtivemos:

Figura I - Indução do cliente à realização de procedimento inadequado

\section{1-Você induziria o cliente a realizar um procedimento, mesmo sabendo que não é o ideal à situação que ele apresenta?}

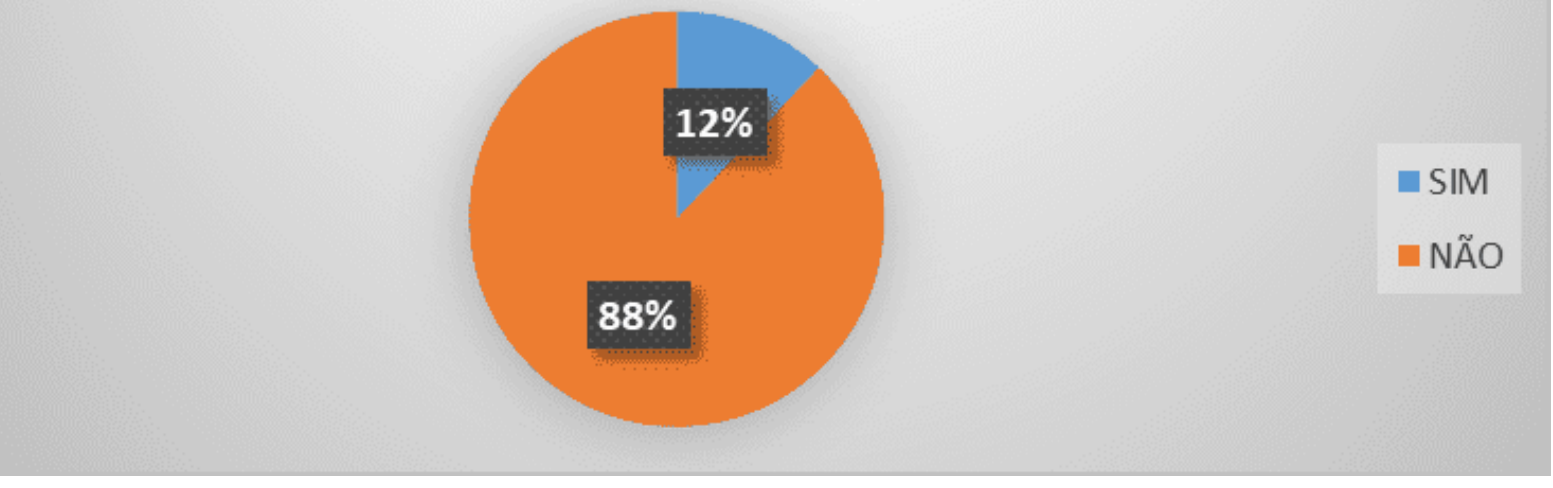

Fonte: A autora (2018).

Diante da questão acerca do induzimento à realização de procedimento inadequado ao problema apresentado pelo cliente, $88 \%$ da população questionada alegou que não induziria o cliente a tratamento insatisfatório, enquanto 12\% afirmaram que induziriam.

Agir com ética na informação ao cliente consiste no discernimento para encontrar o critério da escolha justa (SOUZA, ARAÚJO, 2015). Os resultados obtidos informam que a maioria dos profissionais de estética oferece ao cliente o procedimento que proporcione melhor efeito à sua necessidade. 
Figura II - Atos antiéticos entre profissionais de estética

\section{2-Já presenciou ato antiético (causar constrangimento a colega de profissão) afim da obtenção de lucro e/ou posição no ambiente de trabalho?}

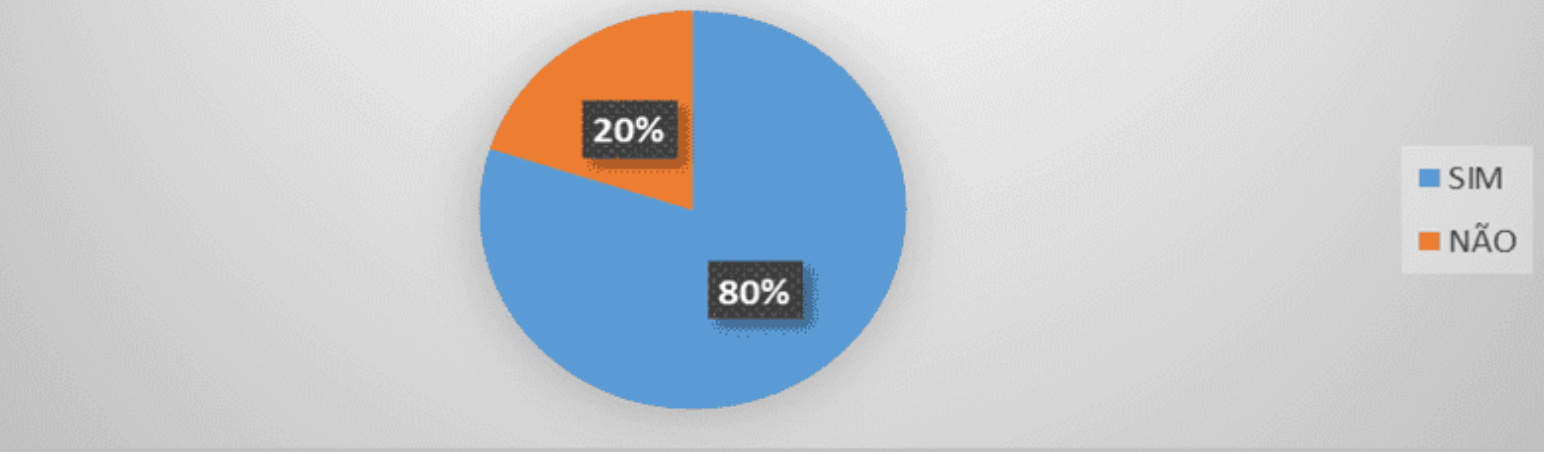

Fonte: A autora (2018)

Perguntados se já haviam presenciado ato antiético entre colegas de profissão, 80\% informaram que sim, enquanto $20 \%$ não presenciaram tal situação. Menosprezar o trabalho alheio ou causar qualquer tipo de constrangimento a colega de profissão, visando conseguir para si o seu emprego, cargo ou função, consiste em ato desleal e antiético (FEBRAPE, 2003, art.4ํㅡㄴ. $\mathrm{VI}$ ). Apesar da existência de normas que regem a profissão, observou-se que a maioria dos profissionais não as colocam em prática como deveriam, ocasionando assim, uma postura antiética (SOUZA, ARAÚJO, 2015). 
Figura III - Divulgação de informação sigilosa

\section{3-Já ouviu de outra profissional, alguma informação de cliente que deveria ser sigilosa?}

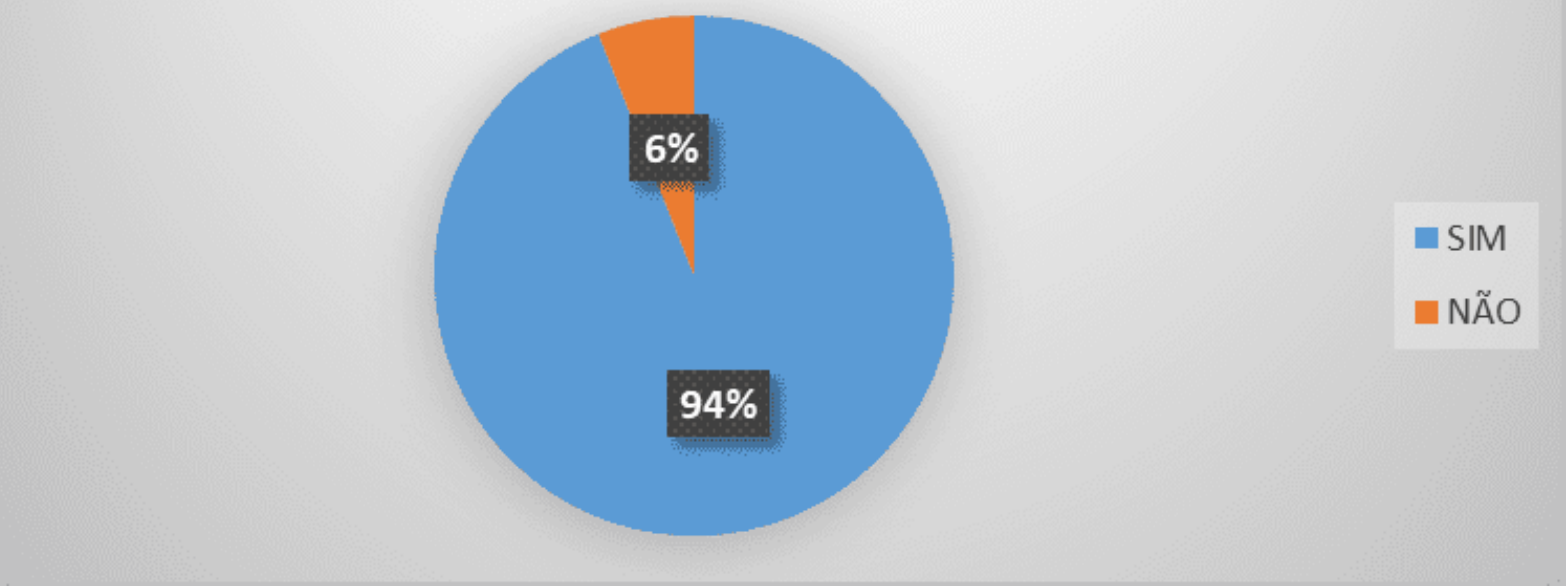

Fonte: A autora (2018)

Questionados acerca da divulgação de informação sigilosa, 94\% dos acadêmicos atuantes na área afirmaram já ter ouvido informações de profissionais sobre seus clientes, enquanto $6 \%$ negaram ter ouvido informações desta espécie.

A confidencialidade pressupõe que o indivíduo, ao compartilhar informação, esta deve ser respeitada e utilizada somente para o propósito para o qual foi revelada (STYFFE, 1997). Notou-se que grande maioria dos profissionais, possui atitude antiética no sentido de não guardar sigilo das informações que recebe em confidencialidade do cliente. 
Figura IV - Importância da existência de um código de ética para a profissão de esteticista

\section{4-Você considera importante a existência de um código de ética na profissão de tecnólogo em estética?}

Fonte: A autora (2018)

Da população entrevistada, 92\% acredita ser importante a existência de um código de ética na profissão de tecnólogo em estética, enquanto $8 \%$ não considera a sua importância. De acordo com esse resultado, observa-se que grande maioria dos profissionais se preocupa em trabalhar de acordo com o documento que compila os valores que a cultura de uma determinada sociedade considera necessários para que seus membros possam interagir (MAIO apud SOUZA, ARAÚJO, 2015, p.11).

\section{CONSIDERAÇÕES FINAIS}

Os resultados obtidos demonstram de forma clara que, a grande maioria dos futuros profissionais da área de estética da Universidade Tiradentes, já atuantes na área, possuem ciência da importância da existência do Código de Ética, e desenvolvem suas atividades de acordo com o que ele preceitua. Infelizmente, 06 dos entrevistados 
induziriam seus clientes a realizar procedimentos sem relutância, e 04 acreditam que o Código de Ética é dispensável.

Como estes dados foram de questionamentos direcionados a atitudes morais e educativas do próprio estudante, percebe-se que, por mais que a Universidade Tiradentes transmita e debata ao longo do curso acerca das formas corretas de agir, formas que são conhecidas de qualquer ser humano, alguns ainda optam por ser antiéticos. Por outro lado, quando questionados sobre atitudes de terceiros, os resultados foram desastrosos. Atos antiéticos entre colegas de profissão visando lucro e desrespeito ao sigilo profissional precisam ser combatidos.

O objetivo desta pesquisa foi alcançado, pois identificou junto a alunos do curso de Estética e Cosmética da Universidade Tiradentes atuantes na área, a percepção da ética no exercício da profissão. O que se espera é que, com a inserção de Tecnólogos em Estética cada vez mais capacitados e especializados no mercado de trabalho, haja um crescimento gradual da conscientização moral daqueles que prestam seu serviço de forma antiética, seja na anamnese, na biossegurança, no contexto comercial, no sigilo profissional e na conduta profissional, bem como pela busca de conhecimento para que a profissão seja cada vez mais respeitada.

\section{REFERÊNCIAS}

ARRUDA, M. C. C. de; WHITAKER, M. C.; RAMOS, J. M. R. Fundamentos de ética empresarial e econômica. 3. ed. São Paulo: Atlas, 2003.

ARRUDA, M. C. C. de; WHITAKER, M. C.; RAMOS, J. M. R, 2003. ANVISA. Agência Nacional de Vigilância Sanitária, São Paulo, Lista de medicamentos sujeitos a notificação simplificada. Disponível

em: http://www.anvisa.gov.br/servicosaude/manuais/manual_seg_hosp.htm Acesso em 21 de agosto de 2018.

ASSOCEMSP. Associação dos profissionais de cosmetologia, estética e maquilagem do Estado de São Paulo, Código de Ética dos Profissionais de Estética, São Paulo, 
Disponível

em:

http://www.sindestetica.org.br/wpcontent/uploads/2018/01/C\%C3\%93DIGO-DE-ETICA-DA-PROFISS\%C3\%83O.pdf Acesso em 21 de agosto de 2018.

BALDUINO, P. M.; PALIS, F. P.; PARANAÍBA, V. F.; ALMEIDA, H. O.; TRINDADE, E. M. V. A perspectiva do paciente no roteiro de anamnese: o olhar do estudante. Rev. Bras. Educ. Med. 2012;36(3):335-342. Disponível em: http://www.scielo.br/pdf/rbem/v36n3/07.pdf . Acesso em 28 de julho 2018.

BARROS, M. F. R. A ética no exercício da profissão contábil. 2010. Monografia (Bacharelado em Ciências Contábeis) - Instituto de Ciências Econômicas e Gerenciais, Pontifícia Universidade Católica de Minas Gerais, Belo horizonte, 2010. Disponível em: http://sinescontabil.com.br/monografias/trab_profissionais/rosiane.pdf Acesso em 22/10/2018.

BASTOS, A. V. B.; YAMAMOTO, O. H.; RODRIGUES, A. C. A. Compromisso social e ético: desafios para a atuação em psicologia organizacional e do trabalho. Borges \& Mourão (orgs.). 2015.2 Disponível em: http://www.larpsi.com.br/media/mconnect_uploadfiles/c/a/cap_01ccc.pdf . Acesso em 21 de agosto de 2018.

BATAGLIA, P. U. R.; BORTOLANZA, M. R. Formação profissional e conceitos de moral e ética em estudantes de psicologia. Revista Psicologia: teoria e prática, São Paulo, v. 14, n. 2, p. 126-140, 2012. Disponível em: http://pepsic.bvsalud.org/scielo.php?script=sci_arttext\&pid=S1516-

36872012000200011 . Acesso em: 01 de agosto de 2018.

BICKLEY, L. S. B. Propedêutica Médica / Lynn S. Bickley; Peter G. Szilagyi; tradução Maria de Fátima Azevedo. - 11. ed. - Rio de Janeiro: Guanabara Koogan, 2015, p.85. Disponível em: file://C:/Users/trici/Downloads/Bates,\%20Proped\%C3\%AAutica\%20M\%C3\%A9dica \%20(Bickley)\%2011.\%20ed.\%20-\%20www.meulivro.mobi.pdf

BRASIL. Constituição Federal. Brasília: Senado Federal, 1988. 
BRASIL. Código Penal. Decreto-lei n. 2.848, de 7 de dezembro de 1940. In Vade mecum penal e processual penal. 3를 ed. Niterói, RJ: Impetus, 2012.

CHAUI, M. Convite à Filosofia. Ed. Ática, São Paulo, 2000, p.89. Disponível em: http://home.ufam.edu.br/andersonlfc/Economia_Etica/Convite\%20\%20Filosofia\%20\%20Marilena\%20Chaui.pdf

COHEN C.; SEGRE M. Definição de valores, moral, eticidade e ética. In: Segre M, Cohen C, organizadores. Bioética. São Paulo: EDUSP; 1995. p.13-22

D'EPHÈSE R. De L'intérrogatoire Des Malades. In: Oeuvres De Rufus D'ephè se. Paris: Imprimerie Nationale,1879:196-218.

D’ESPINDULA, T. C. A. S. Privilégio terapêutico e os códigos de ética médica brasileiros: uma reflexão bioética. 2017, p.9. Dissertação (Pós-Graduação em Bioética) - Escola de Ciências da Pontifícia Universidade Católica do Paraná. Disponível em: http://www.biblioteca.pucpr.br/pergamum/biblioteca/img.php?arquivo=/000061/00006 15e.pdf

DOTTO, M. L. G. Comportamento Ético do Profissional de Contabilidade: Pesquisa no setor hoteleiro de Cascavel - PR. 2002. 152f. Dissertação (Mestrado Engenharia de Produção) - Universidade Federal de Santa Catarina, Florianópolis. Disponível em: https://repositorio.ufsc.br/xmlui/bitstream/handle/123456789/82763/189498.pdf?sequ ence $=1$ \&isAllowed $=y$

FEBRAPE. Federação Brasileira dos Profissionais Esteticistas, 2003. Disponível em: http://febrapeestetica.blogspot.com/p/codigo-de-etica-profissional-do.html Acesso em 21 de agosto de 2018.

FERREIRA, A.B.H. Novo dicionário Aurelio, versão 5.0; 2006.

GRACIA, D. Fundamentos de bioética. Madrid: Editorial Triacastela, 2007. 
GRACIA, D. La confidencialidad de los datos genéticos. In: Gracia D. Ética y vida: ética de los confines de la vida. Santa Fé de Bogotá: Buho; 1998. p. 137-50.

JOHNSON, I. L.; DWYER, J. J. M.; RUSEN, I. D.; SHAHIN, R.; YAFFE, B. Survey of Infection Control Procedures at manicure and Pedicure Establishments in North York. Rev Canad de Saint Pub, v. 92, n. 2, p. 134-137, 2001.

KOTTOW, M. H. Stringent and predictable medical confidenciality. In: Gillon R. Principles of health care ethics. Chichester: John Wiley and Sons; 1994. p. 471-8

LISBOA, 1997, apud, DANTAS, B. E. ÉTICA NA CONTABILIDADE: proposta de adoção de princípios de conduta em empresa pública de administração indireta. Belo Horizonte, 2013.

Disponível em:

http://www.sinescontabil.com.br/monografias/trab_profissionais/eticanacontabilidade-proposta-adocao.pdf . Acesso em 29 de julho de 2018.

LOCH, J. A. Confidencialidade: natureza, características e limitações no contexto da relação clínica. Rev. Bioética. 2003;11(1):51-64.

MAIO, M. Tratado de medicina estética, 2.ed. São Paulo: Roca, 2011.

MEC. Introdução aos parâmetros curriculares nacionais. Brasília: MEC/SEF, 1998.

MOTTA, N. S. Ética e vida profissional. Rio de Janeiro: Âmbito Cultural, 1984, p.69.

NEVES, T. P.; PORTO, M. F. S.; MARINHO, C. L. C.; BRAGA, A. M. C. B. O conceito de biossegurança à luz da ciência pós-normal: avanços e perspectivas para a saúde coletiva. Saúde Soc., São Paulo, v. 16, n. 3, p. 158-168, 2007.

OLIVEIRA, M. C. S. M. de et al. A importância e o conhecimento sobre ética: o olhar de discentes do curso de Ciências Contábeis. Belo Horizonte, 2010, p.1. Disponível em: https://anaiscbc.emnuvens.com.br/anais/article/download/837/837

PEDRO, A. P. Ética, moral, axiologia e valores: confusões e ambiguidades em torno de um conceito comum. Kriterion: Revista de Filosofia, Belo Horizonte, v. 55, n. 130, 
p.

483-498,

dez.

2014.

Disponível

em:

http://www.scielo.br/scielo.php?script=sci_arttext\&pid=S0100-512X2014000200002 Acesso em 22/10/2018.

PERES, S. H. C. S. Sigilo profissional e valores éticos. Revista RFO, v.13, n.1, p.713, janeiro/abril 2008. Disponível em: http://seer.upf.br/index.php/rfo/article/view/583 . Acesso em 28 de julho de 2018.

RICOEUR, P. Éthique et Morale. Revista Portuguesa de Filosofia, tomo XLVI, fasc. 1, Janeiro-Março 1990, pp. 5-17 [Publicado também em Lectures 1, Autour du politique. Paris: Seuil, 1991, pp.258-270]. Disponível em: http://www.scielo.mec.pt/scielo.php?script=sci_nlinks\&ref=000108\&pid=S0807$8967201200020002700004 \& \operatorname{lng}=\mathrm{pt}$

SOUZA, L. R. M; ARAÚJO, F. Q. Ética profissional no contexto da estética e beleza. 2015. p.19. Curso de tecnologia em estética e imagem pessoal. Universidade Tuiuti do Paraná, Curitiba, 2015.

STYFFE, E. J. Privacy, confidenciality, and security in clinical information systems: dilemmas and opportunities for the nurse executive. Nurs Admin Q. 1997; 21: 21-8.

SWARTZ, M. H. Tratado de semiologia médica: História e exame clínico, 7 ed. Elsevier, 2015. Cap.1: As Questões da anamnese, p.5-6.

TONETA, P.; AGOSTINI, V. W. A preocupação com a biossegurança em clínicas de estética e salões de beleza. Anuário de Pesquisa e Extensão da Unoesc Videira, v.2, p. 1-14, 2017.

WAZIR, M. S.; MEHMOOD, S.; AHMED, A.; JADOON, H. R. Awareness among barbers about health hazards associates with their profession. J Ayub Med Coll Abbottabad, v. 20, n. 2, p. 35-8, 2008. 


\section{APÊNDICE}

\section{QUESTIONÁRIO APLICADO}

Questionário

Universidade Tiradentes

Você está convidado(a) a responder este questionário, composto de quatro perguntas objetivas, que fará parte da coleta de dados da pesquisa cujo título é "A importância da ética profissional do esteticista no relacionamento com o cliente", sob responsabilidade da acadêmica do curso de Estética e Cosmética da Universidade Tiradentes, Patrícia de Campos Goes.

Não será preciso identificar-se.

Perguntas:

1. Você induziria o cliente a realizar um procedimento, mesmo sabendo que não é o ideal à situação que ele apresenta?

( ) SIM ( ) NÃO

1. Já presenciou ato antiético (causar constrangimento a colega de profissão) afim da obtenção de lucro e/ou posição no ambiente de trabalho?

( ) $\operatorname{SIM}($ ) NÃO

1. Já ouviu de outra profissional, alguma informação de cliente que deveria ser sigilosa?

( ) $\operatorname{SIM}($ ) NÃO

1. Você considera importante a existência de um código de ética na profissão de tecnólogo em estética? 
( ) SIM ( ) NÃO

Enviado: Maio, 2019.

Aprovado: Julho, 2019. 